\title{
Student's general attitude in gender-inclusive language
}

\author{
Ma. Theresa R. Remigio, Arlene D. Talosa \\ College of Teacher Education, Cagayan State University-Aparri, Philippines
}

\begin{tabular}{l}
\hline Article Info \\
\hline Article history: \\
Received Jan 15, 2021 \\
Revised Jun 18, 2021 \\
Accepted Jul 13, 2021 \\
\hline Keywords: \\
Gender difference \\
Gender-inclusive language \\
Non-sexist language \\
Sexism \\
Sexist language
\end{tabular}

Article Info

Article history

Received Jan 15, 2021

Revised Jun 18, 2021

Accepted Jul 13, 2021

\section{Gender-inclusive language \\ Sexism}

\begin{abstract}
Centered on studies on language and gender, this study generally aimed to assess the students' general attitude towards Gender-Inclusive It likewise determined difference on attitude when grouped according to sex. The study utilized quantitative research design. Survey questionnaire using the IASNL was the instrument used which assesses beliefs, recognition of sexist language and willingness to use gender-inclusive language. Respondents utilized were randomly selected students of the College of Teacher Education. Results revealed that most of the students were female, displaying a positive attitude towards gender-inclusive language which indicates the students' openness to gender-inclusive language use. It was found though that women and men did not seem to care strongly one way or another about gender-inclusive language. The result is reflective of the potential positive feedback to the Gender and Development (GAD) mainstreaming programs of the campus on the use of the said language.
\end{abstract}

This is an open access article under the CC BY-SA license.

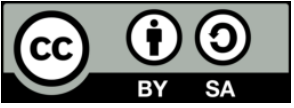

\section{Corresponding Author:}

Arlene D. Talosa

Graduate School and College of Teacher Education

Cagayan State University

Maura, Aparri, Cagayan, Philippines

Email: enelasolat@gmail.com

\section{INTRODUCTION}

Literatures provide mounting evidence that language plays a crucial factor in molding linguistic behavior and gender perceptions. Women and their image, as Hansen, Littwitz, and Sczesny [1] argued are not only influenced by what is said or not said about them, but also by how it is said. Sexism in language is not an isolated social practice. Seen in the context of a patriarchal culture and the gender ideology it produces, it emerges as a basic and important issue worthy of reform.

Both literature, education and the education sector in language planning and language reform are established as key catalysts for adopting, introducing and propagating the Language Reform, Pauwels and Winter [2] Furthermore, the educational sector was readily established as a strong place for communicating sexist and non-sexist language activities during the discussion on linguistic discrimination and non-sexist change. It has been said that lexical terms people choose do matter, Sabater [3]. The use of generic masculine is not simply a linguistic convention, involving other discursive practices, in other words, they imply a discursive tendency to exclude and or misrepresent those who belong to specially marked subcategories like women.

Gender - Inclusive language is a way of acknowledging diversity, respecting all individuals, being sensitive to differences and promoting equality of opportunities. Special attention is currently being paid to using gender-inclusive language in almost all forms of discourse internationally. Such is now the standard practice giving birth to numerous studies due to variated campaigns. Circular Memorandum No. 12, s. in the Philippines Civil Service Committee, 2005 [4] encourages all government organizations, including gender language consumers, to stop unequal use of languages. Recent studies conducted by Clemente and Temporal 
[5] concluded that teacher education faculty are gender-inclusive language competent along formal register, non-sexist terms on roles, and non-sexist terms in context. More so, Shehabat [6] recently argued that women's voices have long been ignored, silenced and suppressed due to their gender, a notion Noman and Asthana [7] attributed to women's social structure. Similarly, on a study embarked by Ruanan and Jun [8] on social construction in Political context, they further speculated that candidates of differing genders have distinct awareness of social gender creation in public discourse which they use to question or neutralize public gender assumptions. A review of worldwide gender representatives' studies in primary school books meanwhile proves that there are still gender stereotypes, as Teliousi, et al. [9], argued at least in course books. This all proves that de-gendering of language due to gender-inclusivity is still at its high peak of special interest attracting the attention of linguists around the globe. Also, in the Philippine context, Tarrayo [10] argued that there is a crucial role expected among teachers in preventing gender discrimination from sneaking into the classroom.

Recognizing the ways in which linguistic inequality reinforces gender and other inequalities is essential to developing a culture of inclusiveness although mounting evidence suggests that gender inequality is perpetuated by language, Harris, et al. [11]. This linguistic inequality is shown in paradigm shift whereby foodsemic terms can also be used in reference to both genders in a sexist way through the use of metaphorical transfers' attributive to women as argued by Lilian [12]. Guder and Ata [13] determined that there too is a significant positive relation between the gender stereotypes of the child and their father's arbitrary engagement, which is one of the sub-dimensions of the father involvement scale thus the need for proper modeling. Language is a linguistic tool capable of molding, shaping and representing realities in the society lived into, He [14]. With this, Ariyanto [15] and Widodo, et al. [16] asserted that social actors at different levels of education from primary to tertiary education play a pivotal role in canalizing or imposing particular values through educational practices and documents.

Spontaneous use of gender inclusive language has been shown to be driven by clear intentions to use gender inclusive language as well as by a subtler mechanism involving its use in the past [17]. Scientific writings call for the desideratum not to condone once ubiquitous practices that, either consciously or unconsciously, act to the detriment of gender-inclusive fairness yet calling for importance is the fact that attitude plays in the formation and reformation of habits.

While the study of Gender-inclusive language is a growing concern among researchers across countries as a robust body of literature on the said language is available. Few researchers ventured on determining the attitude of students towards gender-inclusive language in the Philippine context. Just recently, Talosa and Temporal [18] in their study on content analysis of sexist language occurrence on students written discourse found that there are incidences of sexist language in students' discourse, generic masculine of which appear to be the most recurrent showed an alarming deviance of the linguistic trend which shows its possibility to form a habit if not being corrected in the course of their learning. They also pointed out that while English is the most commonly used foreign language in the world, it is imperative for language users to be responsive to gender-based languages.

In the Cagayan State University, efforts are now undertaken to address gender and development (GAD) concerns which include the use of inclusive language. According to The Writing Center of the University of North Carolina [19] "writers today must think more carefully about the ways they express gender in order to convey their ideas clearly and accurately to their readers". It is sad to note however that despite wealth of evidence that male generic terms negatively impact the conception of women, inclusive terminology remains to be contested [20].

Sociolinguistics have considered language attitudes as one of the major factors manipulating language variation and change. Most specifically, the study delved into determining sex differences on the attitude of the students in Gender-Inclusive language so as to see whether there is a gap among men and women on the attitude towards de-sexing the English language which is generally believed to be a primary perpetuator of gender-exclusive language.

The present study assessed the attitude of the students in gender-inclusive language. Specifically, it sought to answer the following questions: 1) What is the sex profile of the students? 2) What is the attitude of the students in gender-inclusive language? (Belief in Gender-exclusive language); Recognition of Genderexclusive language; Willingness to use gender-inclusive language); 3) Is there a significant difference on the student's attitude in gender-inclusive language when grouped according to sex? 4) What pedagogical intervention may be inferred from the findings? 


\section{RESEARCH METHOD}

The study utilized the descriptive-comparative research design. Descriptive was used on the profile of the students including their attitude towards gender-inclusive language. Comparative on the other hand was used in determining a significant difference between the students' general attitude. The study respondents were students of a State Institution in Cagayan. The key method used to collect the data was the survey questionnaire, which was split into two sections. The 21 products of the Inventory of Attitudes toward Sexist and Non-Sexist Language - General (ISANL-G), a questionnaire which went through face and content validation and with excellent internal consistency by Parks and Roberton [21], [22] was adopted in the study. Psychometric properties of the instrument are excellent. The Cronbach alpha of (.80) indicates a high degree of internal consistency. Prior to the data collection, written directions were given to the participants and they were told of their voluntary involvement in the study and of their right to decline. Each participant received general directions, research details, purpose and confidentiality agreements, all of which were included in the informed consent.

\section{RESULTS AND DISCUSSION}

\subsection{Sex}

Table 1 indicates the gender distribution of students. Table 1 shows that 88 or $73.33 \%$ of students are females with the majority, while only 32 or $26.66 \%$ of students are males. This is supported by college enrolment evidence that there are more female enrolments than male enrolments. It can be deduced from the data that the big English students of the College of Teacher Education are overwhelmingly female. This result indicates that the majority of those who took an apprenticeship are female.

Table 1. Distribution of the students in terms of sex

\begin{tabular}{lcc}
\hline Sex & Frequency $(\mathrm{n}=120)$ & Percentage \\
\hline Female & 88 & 73.33 \\
Male & 32 & 26.66 \\
\hline
\end{tabular}

\subsection{Belief about gender-exclusive language}

Table 2 presents the belief of the students towards gender-exclusive or sexist language. Based on the Table 2, the respondents reportedly accept that while reform is difficult, they should also strive to remove the gender-based language (4.00) and those most publishing standards require newspaper writers to avoid the use of ethnic and racial slurs. Thus, these guidelines may also require writers to avoid gender-based languages (3.60), and also to favor the idea that the manner in which English has historically been written and spoken should not be altered (3.58), which is a pretense that concern regarding the usage of gender-based languages is part of an increased understanding that the perceived significance of such terms has changed in reaction to changing roles. In addition, students have accepted that the abolition of gender-based language is a significant goal; gender-based language is connected to gender-based treatment of people in society; and when teachers speak about the past of the Philippines, they should adjust phrases such as "our forefathers" to expressions that include women, both of which have the same mean of 3.50. Benson, et al. [23] argued that using sexist and unnecessarily gendered language stems to some extent from sexist and traditional gender role beliefs. Endorsers therefore of traditional gender roles are more likely to use sexist language. Worth noting however are students' responses of agreement for the elimination of this language. 
Table 2. Attitude towards sexist and non-sexist language along belief about gender exclusive language

\begin{tabular}{|c|c|c|}
\hline Statements & Weighted mean & Descriptive \\
\hline 1. Women who think that the term 'chairman' is misinterpreted by gender & 3.50 & Agree \\
\hline 2. The way English was traditionally written and spoken should not be modified. & 3.62 & Agree \\
\hline 3. Worrying about sex is a daunting job & 3.40 & Agree \\
\hline $\begin{array}{l}\text { 4. If the original sense of the word "he" was "person," we still need to use "he" to refer } \\
\text { now to both men and women }\end{array}$ & 2.40 & Disagree \\
\hline $\begin{array}{l}\text { 5. The word gender-based should not refer to those using the term 'man and wife' if users } \\
\text { do not mean it is a sexual orientation }\end{array}$ & 3.40 & Agree \\
\hline 6. English is never modified because it is so culturally ingrained & 3.30 & Undecided \\
\hline 7. Eliminating gender is an important objective & 3.60 & Agree \\
\hline $\begin{array}{l}\text { 8. The majority of publications need journalists to avoid the use of ethnic and racial slurs. } \\
\text { These guidelines should also require writers to avoid gender language }\end{array}$ & 3.70 & Agree \\
\hline 9. Sexist language has to do with the treatment of people in society based on gender. & 3.60 & Agree \\
\hline $\begin{array}{l}\text { 10. Teachers should turn terms like "our forefathers," into phrases that involve women } \\
\text { when they speak about Philippine culture }\end{array}$ & 3.60 & Agree \\
\hline $\begin{array}{l}\text { 11. Teachers who require students to use nonsexist language are unfairly forcing their } \\
\text { political views upon their students }\end{array}$ & 3.50 & Agree \\
\hline 12. While changes are difficult, the vocabulary based on gender should also be removed & 4.00 & Agree \\
\hline Overall mean & 3.45 & Agree \\
\hline
\end{tabular}

\subsection{Recognition of the students in gender-exclusive language}

When asked about the recognition of the students towards gender-exclusive language, Table 3 reveals that the students regarded all the underscored statements as somewhat sexist. The generic 'he' (4.0), chairman (3.90), 'mankind', and 'old wives' both of which have a weighted mean of 3.60. This finding means that the students limitedly recognize sexist terms. Hence, the finding implies that they are not critically aware of gendered language. Such belief or attitude is critical because unawareness of sexist terms in language results to deliberate use or implementation of such. This result supports the argument that, despite attempts to make language gender equal, the use of gender-based language still as Gender-fair language strategies often faces resistance as mentioned by Vergoossen, et al. [24]. There is also a need to consider the value of transforming language from conventional to more liberating, gender-sensitive use.

Table 3. Recognition of sexist language

\begin{tabular}{lcl}
\hline Statements & Weighted mean & Descriptive value \\
\hline 1. People should think for all humanity, not just themselves & 3.80 & Somewhat sexist \\
2. The idea that frogs can give you warts is just an old wives' tale & 3.70 & Somewhat sexist \\
3. If the child wants to play the piano well, he has to practice hard & 4.00 & Somewhat sexist \\
4. Juana DelaCruz should be chairman of our committee & 4.00 & Somewhat sexist \\
Overall mean & 3.88 & Somewhat sexist \\
\hline
\end{tabular}

\subsection{Willingness of the students towards use of gender inclusive language}

As regards to the willingness of the students in using gender fair language, Table 4 unveils that the students are very willing to use the expression "husband and wife" rather than "man and wife" with a mean of 4.20 which suggest their utmost willingness to use hierarchic expression or symmetrical construction. Consequently, as the respondents are English majors, they are highly aware of parallel structures as they study this in most of their subjects which dealt with structures of English. Moreland [25] posited that familiarity and exposure breeds liking thus the awareness may change the longer gender-fair language have been used. Table 4 further exposes that the students are somewhat willing to use the term "camera operator" rather than "cameraman, and use the title "flight attendant" instead of "steward" or "stewardess". The title to a married woman as "Ms. Smith" rather than "Mrs. Smith" (3.30) was regarded as undecided. This undecidedness merits special attention in scientific and technical writing, where any ambiguity is unacceptable.

Table 4. Willingness to use gender-fair language

\begin{tabular}{|c|c|c|}
\hline Statements & Weighted mean & Descriptive mean \\
\hline $\begin{array}{l}\text { 1. When you are referring to a married woman, how willing are you to use the title "Ms. } \\
\text { Smith" rather than "Mrs. Smith"? }\end{array}$ & 3.50 & Undecided \\
\hline 2. How willing are you to use the word "server" rather than "waiter" or "waitress"? & 3.80 & Somewhat willing \\
\hline 3. How willing are you to use the expression "husband and wife" rather than "man and wife"? & 4.40 & Very willing \\
\hline 4. How willing are you to use the term "camera operator" rather than "cameraman"? & 4.20 & Somewhat willing \\
\hline 5. How willing are you to use the title "flight attendant" instead of "steward" or "stewardess"? & 4.30 & Somewhat willing \\
\hline Overall mean & 4.04 & Somewhat willing \\
\hline
\end{tabular}




\subsection{General attitude in gender-inclusive language}

Table 5 reveals the general attitude of the students in Gender-inclusive language. Following the scale of scores, 76 or $63.3 \%$ of them showed a supportive attitude to gender-inclusive language while 43 or $25.8 \%$ of them revealed a neutral attitude to it. Meanwhile, there was only one or $.83 \%$ who exhibit a negative attitude towards the language. This finding indicates that the majority of the students manifest a supportive attitude to the language. This finding implies that the respondents are supportive of language reform through Gender-inclusive language. Mucchi-Faina [26] posited that resistance to the use of genderinclusive alternatives can take the form of refusal to change the language. Supportive attitude to Gender Inclusive Language therefore breeds positivity to language reform.

\begin{tabular}{|c|c|c|}
\hline Attitude & Frequency $(\mathrm{n}=120)$ & Percentage \\
\hline Supportive attitude & 76 & 63.3 \\
\hline Neutral attitude & 43 & 35.8 \\
\hline Negative attitude & 1 & .83 \\
\hline
\end{tabular}

\subsection{Differences on belief in sexist language when grouped according to sex}

The research hypothesized that the confidence of students in the equal language of gender and their sex does not vary significantly. Table 6 shows that the confidence of students in sexist languages does not vary substantially if they are grouped according to their sex and according to their t-values -1.04 with a probability of 0.303 , which is above the set 0.05 mark. Consequently, the null hypothesis is accepted. This finding means that sex has no significant bearing with the attitude of the students towards gender fair language. This finding supports the study surveyed by Talosa [27] as she found that women and men did not seem to care strongly one way or the other about gender-fair language.

Table 6. Difference of the student's belief in sexist language when grouped according to sex

\begin{tabular}{llll}
\hline \multicolumn{4}{c}{ Belief of the students in sexist language } \\
Sex & Mean & t-value & Probability \\
\hline Male & 3.46 & & \\
Female & 3.34 & 1.04 & 0.303 \\
\hline
\end{tabular}

The research assumed that the students' acknowledgement of the sexual equity vocabulary would not have a major gender gap. Table 7 shows that the recognition of sexist language of students as calculated by its 1.90 -value with the likelihood of 0.06 is not important. This result indicated that the appreciation of the sexist vocabulary was irrelevant for both men and women. The first step to change the use of genderinclusive language was to acknowledge in language and gender literature the problematic field, which states: "If students can't identify gender-specific languages or stereotypes, they wouldn't know how to use them even if they know non-sexist terminology." Kuhn and Gabriel [28] find that the language competence of individuals, not gender, predicts that they will use sexual equality, which is consistent with finding that it is difficult to use gender equality language, and that linguistic skills are an important prerequisite in the use of gender-inclusive language.

Table 7. Difference of the student's recognition in gender fair language when grouped according to sex

\begin{tabular}{llll}
\hline \multicolumn{4}{c}{ Recognition of sexist language } \\
Sex & Mean & t-value & Probability \\
\hline Male & 3.93 & & \\
Female & 3.63 & 1.90 & 0.06 \\
\hline
\end{tabular}

The study theorized that there is no significant difference on the students' willingness in genderinclusive language use when grouped according to sex. Table 8 reveals that there is no significant difference on students' willingness in gender-inclusive language use. This finding indicates that no gender is superior in their willingness to use gender-inclusive language (GIL). This finding supports the results found by Koeser and Sczesny [29] that there is no gender difference in attitudes toward GIL contrary to most findings that women could be expected to hold more favorable attitudes toward GIL than men and they might be more inclined to use it in their own speech. The use of GIL is predicted by: 1) Conscious, explicit judgments, when 
speakers adjust their behavior to their favorable intentions; and as well as 2) More implicit, habitual processes, when speakers simply repeat what they have done previously in similar situations. Contributory to this, a similar study conducted by Sarrasin, et al. [30] disclosed that time was the most important predictor of the attitudes, even after controlling for various other factors.

Table 8. Difference of the student's willingness in gender fair language when grouped according to sex

\begin{tabular}{clll}
\hline \multicolumn{4}{c}{ Willingness to use gender fair language } \\
\hline Sex & Mean & t-value & Probability \\
Male & 3.91 & & \\
Female & 3.86 & 0.36 & 0.717 \\
\hline
\end{tabular}

\subsection{Pedagogical implication}

People regardless of gender are capable and powerful linguistic agents. A small shift in how language is used can advance social change-or signal change that may be on its way to reformation. Having found a supportive kind of attitude of gender-inclusive language, cultural shift in the gender terminology in language should be practiced in continuity. With emphasis on the display of attitude as reflective of habit formation, language education in Tertiary Education curriculum should continue striving for achieving gender inclusivity linguistic perfection. It is on this ground that language teachers, students, administrators should continue to make a good faith effort for this linguistic status quo. To seek consultation when one is unsure and admit humbly and openly when one erred is a dire need. The onus is on all of us to challenge our biases and do better and think critically about gender and language. The mere phenomenon of exposure to a stimulus is enough to reinforce attitudes towards that stimulus, hence, to strengthen the language reform, teachers are in a unique position for modelling, thus the challenge. It is in this prospects that teachers may directly or indirectly include the principles of linguistic registers, which may be a solid ground for the students to be wary of their lexical choices leading to strong linguistic attitude. Likewise, an institutional policy should be formulated enjoining teachers to model gender-inclusive language in their utterances among students and peers.

\section{CONCLUSION}

The study reveals that majority of the students exhibit a positive attitude towards gender-inclusive language. Further, there was no significant difference on the students' attitude when grouped according to sex which indicates neutrality of attitude in either sex. Looking at the lens of instruction, it is worth highlighting that another study should be conducted looking on the effective strategies employed by teachers in perpetuating gender-inclusive language in the language classroom. In this context, teachers need to critically choose, adapt and apply the most suitable teaching materials, and select methods, strategies or techniques that are gender inclusive-sensitive in course designing.

Subsequently, the institution should continue its programs on gender-fair language use to further strengthen the students' attitude towards gender inclusive language use. Training sessions can be effective medium in informing students. Thus, they must be given seminars or trainings on the use of gender-inclusive language in discourse.

The would-be and current researchers of sociolinguistics and pragmatics may consider this study as a gateway in conducting parallel research or scaled up investigation in terms of wider context and additional variables like looking into the lens of students' willingness and or resistance to use gender-inclusive language on their discourse. Similarly, it might also be worthwhile to look at students' perception on teachers' performance and competence as gender-inclusive language user.

\section{REFERENCES}

[1] K. Hansen, C. Littwitz, and S. Sczesny, "The social perception of heroes and murderers: effects of gender-inclusive language in media reports," Front. Psychol., vol. 7, no. 369, pp. 1-17, 2016, doi: 10.3389/fpsyg.2016.00369.

[2] A. Pauwels and J. Winter, "Gender-inclusive Language Reform in Educational Writing in Singapore and the Philippines: A Corpus-based Study," Asian Englishes, vol. 7, no. 1, pp. 4-20, 2004, doi: 10.1080/13488678.2004.10801128.

[3] C. Sabater, "Research on Sexist Language in EFL Literature: Towards a Non-Sexist Approach," Porta Linguarum, vol. 23, no. 1, pp. 187-203, 2015.

[4] Civil Service Commission's (CSC), "Memorandum Circular No. 12, s. 2005," 2014. [Online]. Available: www.pcw.gov.ph. 
[5] B. Clemente and C. Temporal, "Gender-fair language competence of teacher education faculty," Asian EFL Journal Research Articles, vol. 21, no. 2.3, Mar. 2019.

[6] A. Shehabat, "To Speak Up or Not: A Critical Study of Two Feminist Voices in Light of Women's Empowerment," Linguistics and Literature Studies, vol. 8, no. 5, pp. 229-237, 2020, doi: 10.13189/lls.2020.080501.

[7] A. Noman and S. Asthana, "Womens Voices in Arab-American Literature," Langlit, vol. 2, no. 1, pp. 494-5, 2015.

[8] W. Ruanan and H. Jun, "Social Gender Construction in Political Context: A Corpus-Based Study of Lexical Differences across Genders," Linguistics and Literature Studies, Vol. 8, no. 3, pp. 114-124, 2020, doi: 10.13189/1ls.2020.080305.

[9] V. Teliousi, M. Zafiri and V. Pliogou, "Occupation and Gender Stereotypes in Primary School: The Case of the English Language Coursebooks in Greek Primary Schools," Universal Journal of Educational Research, vol. 8, no. 4, pp. 1135-1148, 2020.

[10] V. Tarrayo, "Gendered Word (Or World): Sexism in Philippine Preschool English Language Textbooks," i-manager's Journal on English Language Teaching, vol. 41, no. 2, pp. 25-32, 2014.

[11] C.A. Harris, N. Blencowe, and D.A. Telem, "What's in a pronoun? Why gender-fair language matters," Annals of Surgery, vol. 26, no. 6, pp. 932-933, 2017, doi: 10.1097/SLA.0000000000002505.

[12] M. A. Lilian, "Sexism of the Jiko (Cooking Stoe), Food and Sexuality: The Fuzzy Conceptual Boundary," Linguistics and Literature Studies, vol. 7, no. 5, pp. 185-196, 2019.

[13] S. Guder and S. Ata, "Father Involvement, Gender Perception and Children's Gender Stereotypes," Universal Journal of Educational Research, vol. 6, no. 8, pp. 1637-1646, 2018.

[14] G. He, "An Analysis of Sexism in English," Journal of Language Teaching and Research, vol. 1, no. 3, pp. 332-335, 2010.

[15] S. Ariyanto, "A portrait of gender bias in the prescribed Indonesian ELT textbook for junior high school students," Sexuality and Culture, vol. 22, pp. 1054-1076, 2018.

[16] H.P. Widodo, M.R. Perfecto, L. V. Canh, and A. Buripakdi, Situating moral and cultural values in ELT Materials: The Southeast Asian context. Springer International Publishing, 2018.

[17] S. Sczesny, F. Moser and W. Wood, "Beyond sexist beliefs: how do people decide to use gender-inclusive language?” Pers. Soc. Psychol. Bull., vol. 41, pp. 943-954, 2015, doi: 10.1177/0146167215585727.

[18] A.D. Talosa and C.M. Temporal, "Content Analysis of Sexist Language Occurrence on Written Discourse of Junior Pre-Service Teachers,” TESOL International Journal, vol. 13, no. 4, pp. 96-103, 2018.

[19] The Writing Center, University of North Carolina College of Arts and Sciences, "Gender-sensitive language," 2012. [Online]. Available: http://writingcenter.unc.edu.

[20] C. Luck, "Linguistic and Literature. Rewriting Language: How Literary Texts can promote inclusive language use," UCL Press., pp. 14-52, 2020.

[21] J. Parks and M. Roberton, "Development and Validation of an Instrument to Measure Attitudes Toward Sexist/Nonsexist Language," Sex Roles, vol. 42, pp. 415-438, 2000, doi: 10.1023/A:1007002422225.

[22] J. Parks and M. Roberton, "Erratum: Inventory of Attitude towards Sexist/Non-Sexist Language-General (IASNLG): A correction in scoring procedures," Sex Roles, vol. 44, no. 3-4, 2001, doi: 10.1023/A:1017376822176.

[23] Benson, Kemp, PIrlott, Coughlin, Forss, and Becherer, "Developing a Nonsexist/Nongendered Language Policy at the University of Wisconsin-Eau Claire1," Feminist Teacher, vol. 23, no. 3, 230-247, 2013, doi: 10.5406/femteacher.23.3.0230

[24] H. Vergoossen, E. Renström, A. Lindqvist and M. Sendén, "Four Dimensions of Criticism Against Gender-Fair Language," Sex Roles, vol. 83, pp. 328-337, 2020, doi: 10.1007/s11199-019-01108-x.

[25] R. L. Moreland and S. Topolinski, "The Mere Exposure Phenomenon: A Lingering Melody by Robert Zajonc," Emotion Review, vol. 2, no. 4, pp. 329-339, 2010, doi: 10.1177/1754073910375479.

[26] A. Mucchi-Faina, "Visible or influential? Language reforms and gender (in)equality," Social Science Information, vol. 44, pp. 189-215, 2005, doi: 10.1177/0539018405050466.

[27] A.D. Talosa, "Filipino ESL Students Androgyny Trait, Awareness and Attitude in Gender-Fair Language," Asian Journal of Science and Technology, vol. 9, no. 10, pp. 8865-8874, 2018.

[28] E. Kuhn and U. Gabriel, "Actual and Potential Gender Fair Language Use: The Role of Language Competence and the Motivation to Use Accurate Language," Journal of Language and Social Psychology, vol. 33, no. 2, pp. 214-225, 2014, doi: 10.1177/0261927X13504297.

[29] S. Koeser, E. A. Kuhn, S. and Sczesny, "Just reading how gender fair language triggers readers' use of gender fair foms," Journal of Language and Social Psychology, vol. 34, no. 3, pp. 343-357, 2015

[30] O. Sarrasin, U. Gabriel and P. Gygax, "Sexism and attitudes toward gender-neutral language: the case of English, French, and German," Swiss J. Psychol, vol. 71, no. 3, pp. 113-124, 2012, doi: 10.1024/1421-0185/a000078. 